\title{
Élites y ciudadanía societaria: una teoría relacional del pluralismo postmoderno
}

M anuel $\mathrm{H}$ errera Gómez

Universidad de Granada

manuel.herrera@educ.mec.es

\section{Resumen}

El estudio de las élites desde las Ciencias Sociales, tradicionalmente ha sido desde el punto de vista del sistema político. Partiendo de la «teoría de las élites» de Pareto y de su conceptualización de la diferenciación social, en el presente artículo se pretende reformular y «actualizar» esta teoría a partir de la «teoría relacional de la sociedad», enfatizando la visión de las élites como fenómeno social pluridimensional. Con ello, pretendemos confirmar la hipótesis de que en las sociedades democráticas modernas no sólo se avanza hacia una nueva diferenciación entre las élites, sino que, a su vez, emergen nuevas élites sociales a las que denominaremos élites «societarias".

Palabras clave: élites, élites societarias, ciudadanía, democracia, modernidad, pluralismo, diferenciación.

\section{Abstract}

From the social sciences perspective, the study of elites has concerned the political system. Pareto's elite theory and social differentiation converge to the «relational theory of society». The article proves the hypothesis that in modern democratic societies, elites are not only differentiated but new elites emerge, these new elites can be called "societal elites".

Key words: elites, societal elites, citizenship, democracy, modernity, pluralism, differentiation.

\section{Sumario}

1. El problema: la pluridimensionalidad de las élites, tipos e interrelaciones ante la emergencia de la sociedad postmoderna

2. D emocracia y élites

3. Las élites en la sociedad democrática moderna y postmoderna
4. La emergencia de nuevas «élites societarias»: poderes sociales de la sociedad civil

Bibliografía 


\section{El problema: la pluridimensionalidad de las élites, tipos e interrelaciones ante la emergencia de la sociedad postmoderna}

En el pasado, las élites han sido objeto de la ciencia política, de la sociología y de otras disciplinas. En cada una de ellas, su observación ha tenido lugar desde el sistema político.

En la actualidad, la llamada «teoría de las élites», 0 «élitism», sigue siendo considerada «un planteamiento intelectual a los fenómenos políticos que gira en torno a la consideración del origen, la naturaleza y el rol de los grupos dirigentes (élites) que actúan en los diversos contextos históricos y ambientales. Conceptual y políticamente, el elitismo traslada a las doctrinas de los padres fundadores de la escuela de las élites, es decir, a clásicos como V. Pareto, G. M osca y R. M ichels». ${ }^{1}$

Gaetano M osca no utiliza el término élite, pero habla de «clase política» y de «clase dirigente». En su pensamiento, la élite es «política» en el sentido de que está íntimamente conectada con el verdadero y constante motor de la historia, o sea, el poder normativo más fuerte en la sociedad que, en su opinión, es político. Su objetivo es «desvelar» la natural eza compuesta de tal poder, basado en factores intelectuales, emotivos y legitimadores del consenso (mediante la «fórmula política»). D e esta forma, contempla el carácter preponderante del poder político, hasta el punto de considerar la necesidad de establecer límites y frenos. Lo indica con el concepto de «defensa jurídica», con el que alude al conjunto de normas, procedimientos e instituciones morales, sociales y jurídicas que tienen como objetivo orientar el ejercicio del poder.

Según M osca, ésta es la «política científica». ${ }^{2}$ En su visión, la clase media, emancipada de las necesidades elementales y económicamente autónoma, puede ser el elemento estabilizador y dirigente de la vida social y pública. La única condición es que sea intelectualmente educada y culta, suficientemente íntegra en el plano de la moralidad civil y en la capacidad de no ceder ante la riqueza. Siempre partiendo de la premisa - antropológica y sociológica, antes que política- de que el poder posee una tendencia intrínsecamente oligárquica.

Por su parte, el acercamiento de Robert M ichels a las élites toma como punto de referencia los partidos políticos y los sindicatos. Aunque su obra más conocida, La sociología del partido político en la democracia moderna (1911), constituya un intento sociológico que concluye en la famosa «ley de hierro de la oligarquía», el argumento, de carácter conjuntamente normativo y ético, es desarrollado en términos políticos. Su modelo es un sistema político perfectamente identificado: la socialdemocracia alemana.

Ciertamente, $M$ ichels puede ser considerado el primer analista organizativo de aquellas sociedades políticas que, en un determinado momento de la modernidad, son los partidos obreros y sus sindicatos. Al mismo tiempo, esta-

2. Véase su obra más conocida, Elementos de Ciencia Política, editada en 1896. 
mos delante de un observador deseoso de más democracia ante la constatación escéptica de que cualquier forma de vida social necesariamente traslada a una forma de leadership, en la que las lógicas organizativas prevarican sus valores, programas y proyectos de personas concretas: «la organización es la causa del predominio de los elegidos sobre los electores, de los gobernantes sobre los gobernados [... ]». Con ello, también M ichels confirma la idea elitista de la pre sencia de una inherente tendencia oligárquica en cualquier «sociedad».

Sin embargo, será Vilfredo Pareto quien desarrolle una teoría de las élites desde una clave mucho más compleja. En su Tratado general de sociología (1916), el sociólogo italiano define el concepto de «élite» en los siguientes términos: «H agamos una clase con aquéllos que poseen los índices más elevados en el ramo de sus actividades, a la que daremos el nombre de clase elegida (élite)». ${ }^{3}$ En párrafos sucesivos escribe: «En el estudio que estamos realizando, sería de gran ayuda dividir esta clase en dos: en una meteríamos a aquéllos que, directa o indirectamente, participan en el gobierno, y que constituirían la clase elegida de gobierno. El remanente será la clase elegida no de gobierno». ${ }^{4}$ Por tanto, distingue entre élite como clase el egida de gobierno (podremos llamarla: «élite política») y élite como clase elegida no de gobierno (élite no política), que forman el estrato superior de la sociedad, estrato que se ubica por encima del estrato inferior 0 «clase no elegida».

El concepto de élite está vinculado a una visión de la estratificación social, o bien a una concepción de la sociedad como estructura de clases sociales. A su vez, a ella es conectada la célebre tesis de la «circulación de las clases el egidas» (circulación de las élites). Las aristocracias son conglomerados históricos que, nacidos como élites políticas, generalmente tienden a decaer ( «la historia es un cementerio de la aristocracia»). C on Pareto, la visión de las élites va a tener como eje una teoría de la diferenciación social. Se empieza a distinguir entre aspectos sociológicos y politológicos, que posteriormente orientará a la reformulación del proceso de emergencia, desarrollo y decadencia.

Pareto contempla a las élites como grupos de origen social (élites sociales), siempre minoritarios, que distinguen a los hombres elegidos; y defiende que el equilibrio de la sociedad nace como resultado de la acción y de la interacción de las élites, especialmente de la posibilidad de asegurar su fisiológica circulación. Sin embargo, manifiesta una vez más el carácter esencialmente «político» de la observación: Pareto, con el objetivo de establecer bajo qué condiciones progresa una sociedad, observa a las élites para comprender quién gobierna a la sociedad, de dónde viene y hacia dónde va. $\mathrm{H}$ asta ahora, quien ha seguido la tradición paretiana, a pesar de haber realizado un trabajo sociológico, siempre ha identificado el problema de la élite con la individuación de «quien manda», 0 «quien guía» a la sociedad y a cada una de sus partes (grupos, organizaciones o sistemas sociales).

4. V. Pareto (1916: cap. XI, párrafos 2032 y 2034). 
En estas páginas nos proponemos «actualizar» la teoría de las élites desde la clave sociológica de la diferenciación social. Lo haremos a partir de la llamada «teoría relacional de la sociedad», 5 que reformula los precedentes paradigmas de referencia. Tomando como punto de partida el desarrollo de este planteamiento, la fenomenología de las élites puede ser descrita, interpretada y analizada como una forma específica de relación social, y no como la atribución de ciertas cualidades a los individuos (los el egidos por cualquier caraterística de superioridad, natural o adquirida) o como producto de mecanismos sociales o leyes, más o menos férreas, de la sociedad.

$N$ os gustaría señalar por qué y cómo las élites son un fenómeno social pluridimensional. Afrontar este por qué y este cómo implica observarlas desde un punto de vista más complejo que el estrictamente político. En efecto, si se mantiene el primado de lo político como sistema de observación, el fin es plantear, como señalan numerosos estudios, la desaparición o la muerte de las élites (políticas). ¿H ay al guien que vea élites políticas en los países avanzados? Para contemplarlas, ésta es nuestra intención, es necesario distinguirlas de otras formas, es decir, de las élites no políticas, y relacionarlas con ellas según nuevas modalidades.

El hilo conductor de nuestras argumentaciones es el siguiente: cuando se dice que las élites ya no existen, implícitamente se está afirmando que el sistema de observación es obsoleto y que es necesario cambiarlo. En segundo lugar, para entender a las élites es preciso tener presentes los criterios de selección de los «mejores» que se afirman en diversos contextos y fases históricas, así como las relaciones entre tales criterios. Se debe prestar especial atención a lo siguiente: si, desde el punto de vista sociológico, los códigos de selección pueden ser abundantes y diversos, la selección es social, es decir, no puede reducirse a la biológica (darwiniana o posdarwiniana), la cultural (en el sentido simbólico de los cultural stadies) o la informativa (comunicacional); sino que debe observarse, al menos potencialmente, como relación social «plena». U na teoría sociológica de las élites debería disponer de una teoría de las ventajas evolutivas comparadas de los diferentes tipos de relaciones sociales desde los que emergen las élites. En tercer lugar, y ésta es nuestra hipótesis, es que en los contextos postmodernos, la relación social en sí misma (es decir, el tener o no relaciones sociales valoradas en sí y por sí) se convierte en un criterio de selección de las élites (de ciertas élites respecto a otras). ${ }^{6}$

\section{Véase P. D ONATI (1991).}

6. ¿Existe una élite que no se fundamente en criterios de superioridad/inferioridad o de inclusión/exclusión? La pista merece la pena ser analizada. Es interesante observar que la competición que da lugar a la selección por las élites puede producirse en términos de exclusión (selección de los más fuertes respecto a los más débiles), pero también en términos de inclusión (es decir, de capacidad de integrar a quien se ubica en una posición inferior o está excluido; en este caso, la selección es solidaria, es un cum-petere solidario, que expresa élites propias). Las nuevas culturas del trabajo, más allá de las actuales polarizaciones entre el fin del trabajo (J. Rifkin) y nuevas destrucciones de los ligámenes sociales en la economía de la flexibilidad capitalista (R. Sennett), constituyen un ejemplo de este tipo de leadership y de élites civiles. 
Si detrás de lo planteado existe al guna certeza, es posible iluminar élites hasta ahora desconocidas en el curso de la historia. N os referimos a aquéllas que se construyen a partir de la producción de «bienes relacionales».7 $\mathrm{M}$ ás que hablar de inestabilidad o fragmentación de las élites, habría que plantear la producción de élites como efectos emergentes. Q uien sostiene que estamos ante un «elitism in anomic societies» (un buen ejemplo es P. Atteslander) tan sólo refleja la despolitización de las sociedades postmodernas, es decir, que el punto de vista de la política ya no es el preponderante, o bien que las élites postmodernas son élites pospolíticas, impolíticas o no políticas. Dicho en otros términos, denuncia - quizás sin quererlo- que las élites ya no nacen del trade off entre mercado y estado, y, en consecuencia, que las virtudes de los mejores ya no las encontramos en estas esferas. ${ }^{8}$

Todo ello es resultado, y ésta es nuestra tesis, del siguiente hecho: la democracia moderna produce una diferenciación compleja de las élites, en la que y por la que debe existir una élite que asume el objetivo específico de gestionar una diferenciación sistémica más amplia. En consecuencia, no sólo se avanza hacia una nueva diferenciación entre élites económicas, políticas y culturales, sino que se abren camino élites sociales que llamaremos élites "societarias". Éstas se desarrollan a partir de dos condiciones: a) por la diferenciación de las élites pluralistas (es decir, aquéllas que se caracterizan por una cultura verdaderamente plural y no sólo son expresión de una pluralidad de élites que podrían no tener una cultura plural); b) por el detrimento de la ciudadanía estatal (del Estado nación) y la afirmación de la ciudadanía societaria. ${ }^{9}$ Si no contemplamos estas nuevas élites societarias, es porque seguimos estando ligados a la vieja ciudadanía esta tal, y no estamos capacitados para reconocer la nueva ciudadanía societaria.

Si se sigue el camino abierto por Pareto, posteriormente desarrollado por Parsons, rápidamente se puede observar que una élite aparece en cada una de las diversas dimensiones relevantes de la vida social. Incluso hasta en el espectáculo. ${ }^{10}$ Recientemente, presentándola como un desarrollo de las llamadas élites «estratégicas», Suzanne Keller ha hablado de los «famosos» (celebrities) como nueva élite. ${ }^{11}$

En efecto, la teoría sociológica de las élites iniciada por Pareto contiene una serie de premisas que merece la pena señalar:

- Una visión de la sociedad como campo de batalla entre los actores por los recursos, especialmente posicionales (ligados al estatus social, como los ingresos, el prestigio o el poder).

- Una determinada concepción de la estratificación social que contempla tanto los procesos de formación de sus unidades (clases, grupos, estratos), sus formas de movilidad, así como los procesos selectivos («electivos»).

7. Sobre el concepto de «bien relacional», véase P. D o NATI (1993: cap. 2).

8. Véase L. O RNAGH (1994).

9. Véase P. D ONATI (1993).

10. Véase F. Albero N I (1973).

11. Véase S. Keller (1992). 
- Una evidente conexión con aquellos modelos de sociedad, llamados «tradicionales» (pre-modernos) y de la primera modernización, que aún no conocen el primado de la diferenciación funcional.

C ada una de estas premisas debe ser matizada en cuanto que cambia el marco desde el que fue formulada la teoría paretiana de las élites. La desaparición de las estructuras y de los procesos de estratificación del pasado también implica la necesidad de cambiar la teoría de las élites. D icho cambio debe tener en cuenta que:

a) Para la formación de los estratos sociales «elegidos» ya no valen solamente los indicadores de estatus típicos del pasado, tales como los ingresos, el prestigio y el poder, emergen otras dimensiones de la vida social que desvelan otros criterios de la selección social en los que es crucial el rol de la relación social qua talis.

b) Cambian los parámetros de comparación entre estos indicadores de estatus elegido, sus interacciones y los efectos emergentes de tales interacciones.

c) Cambian los procesos de atribución y de incentivación para tales indicadores de estatus, y con ello también cambian los parámetros de acceso y de salida de los estratos o clase sociales (la movilidad ya no está ordenada jerárquicamente y según una centralidad).

d) La circulación de las élites ya no tiene lugar según las lógicas conectadas a los viejos modelos de estratificación social.

Todo lo anterior puede quedar sintetizado en la siguiente afirmación: el fenómeno de las élites se opone a los procesos de diversificación y «pluralización» típicos de una sociedad que emerge de las lógicas premodernas y modernas.

Ciertamente, las élites persisten como realidad del poder, pero el poder se diferencia y aumenta su carácter de medio simbólico generalizado de intercambio que no puede ser acumulado (como ya demostró T. Parsons). D e esta forma, las antiguas categorías conceptuales, por ejem plo aquéllas que contraponen las élites a las masas, o que contemplan en los intelectuales la élite que tiene la función de dar una representación simbólica de identidad a la socie dad, cambian de significados, de referentes y de conexiones.

El esquema AGIL, en su reformulación relacional, ${ }^{12}$ constituye una excelente síntesis para «evocar» a las élites, es decir, no sólo para representarlas y clasificarlas, sino para ver el nacimiento y el desarrollo potencial (o sea: el potencial de generatividad) mediante dinámicas interactivas.

Una élite nace en cada una de las cuatro esferas que componen la sociedad: económica, política, social y cultural. Pero, generalmente, son el producto de las interacciones entre estas cuatro esferas. Por este motivo, es mejor com- 
prenderla como relación social que posee cuatro dimensiones analíticas (económica, política, social y cultural). Cualquier élite «juega» con estas cuatro dimensiones. Aún más, la élite en sentido empírico se compone de estas cuatro dimensiones que se relacionan como elementos generativos de una relación emergente.

\section{G \\ Élites políticas}

A

Élites económicas
I

Élites sociales

\section{$\mathbf{L}$ \\ Élites culturales}

Figura 1. Ámbitos y tipos de élites.

Considerados empíricamente, en cada uno de estos ámbitos existen muchos tipos de élites:

- (A) En el ámbito económico: las élites empresariales, sindicales, financieras, etc.

- (G) En el ámbito político: las élites de los partidos y de movimientos políticos no organizados como partidos, etc.

- (L) En el ámbito cultural: las élites religiosas, intelectuales, de las artes, del espectáculo, etc. ${ }^{13}$

- (I) En el ámbito social: aquí es más difícil individuar los tipos de élites que se nos enmarcan. El esquema AGIL nos ayuda a dar una representación mediante el método relacional que incorpora: en primer lugar, mediante la distinción con el resto de efferas (A, G, L); concretamente, las élites en el ámbito de la integración social (I) no deben tener ni un carácter instrumental (propio de A), ni un carácter político (propio de G), ni un carácter cultural (propio de L), sino que deben ser expresión de las normas y reglas sociales que son necesarias para realizar las mediaciones de integración internas a la sociedad, y, en segundo lugar, mediante el juego de los inter-

13. Los ejemplos de las nuevas élites culturales van desde las estrellas de los medios de comunicación hasta los grupos de intelectual es. M uy buenos ejemplos de éstos últimos son el llamado Club de Roma, o bien el Club de los Premios N óbel de la Paz. 
cambios relacionales entre estas cuatro dimensiones analíticas y sus referentes empíricos.

Dicho esto, cuando hablamos de «élites sociales», za qué nos estamos refiriendo? Éste es el objetivo de estas páginas.

\section{Democracia y élites}

Las élites dependen de la configuración que puede adoptar una sociedad. El argumento es amplísimo.

El análisis clásico plantea el problema de las élites en clave esencialmente politológica. M uy conocida es la clasificación de los regímenes políticos en monarquías, oligarquías y democracias. Cualquier régimen posee sus correspondientes élites. Siempre en clave politológica, una clasificación diversa es aquélla que distingue entre totalitarismo, democracia y anarquía. Las élites se nos presentan en términos de principios autoritarios (de determinación de las normas), de principios funcionales de oscilación y mediación siempre provisional e incierta, y de principios «no funcional es» (indeterminación de las normas). Tanto en el primero como en el segundo caso nos encontramos ante «estilos» diversos de configuración de las élites.

D os son los motivos que justifican que, en estas páginas, centremos nuestra atención en las élites de los regímenes democráticos. En primer lugar, porque en estos regímenes el proceso de diferenciación de las élites se encuentra más acentuado, a la par que resulta más interesante de observar. En segundo lugar, porque el fenómeno de las nuevas élites no sólo está ligado al desarrollo de la democracia como forma de gobierno político, sino también como concepción cultural del mundo y como modalidad de vivir y regular la sociedad en sus diversos ámbitos.

A su vez, la democracia presenta diferentes formas históricas de élites. Dentro de cualquier forma histórica, la élite emerge desde procesos morfogenéticos ligados a las interacciones entre las cuatro dimensiones analíticas señaladas (económicas, políticas, sociales y culturales: figura 1). Cada una de estas formas históricas comporta élites diferentes. Pero, generalmente, la emergencia de una élite se debe a un peculiar interplay entre estas cuatro dimensiones.

En democracia, las élites se caracterizan por (véase la figura 2):

- Una creciente diferenciación (más o menos funcional o suprafuncional, más o menos simétrica o asimétrica) entre élites económicas, políticas, culturales y sociales.

- Determinados intercambios entre ellas, intercambios que están más o menos limitados: el intercambio más fuerte se produce entre élites económicas (A) y élites políticas (G); con posterioridad está el intercambio entre élites culturales $(L)$ y élites políticas $(G)$; una élite cultural puede llegar a ser política; menos frecuente es que figuras de élite en política asuman el rol de élite 
A

Élites económicas

\section{G}

Élites políticas

$\uparrow \downarrow$

L

Élites culturales

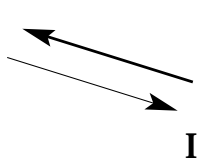

Élites sociales

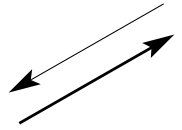

Relaciones más fuertes

Relaciones más débiles

Figura 2. Intercambios entre ámbitos y tipos de élites.

cultural; algo similar sucede entre las élites sociales (I) y las élites políticas $(G)$; desde el punto de vista empírico, otro tipo de posibilidades poseen menos relevancia (muy raro es el intercambio entre élites económicas y sociales, así como entre élites económicas y culturales).

Presentar a las élites como dependientes de regímenes democráticos constituye una operación que sigue estando ligada al punto de vista politológico. M ás aún, se sigue planteando la contraposición entre elitistas y pluralistas. ${ }^{14} \mathrm{Tal}$ contraposición tiene sentido desde la perspectiva de la ciencia política, en cuanto observación orientada a partir del sistema político. Pero desde el punto de vista sociológico, es decir, de una observación orientada desde el punto de vista del sistema societario, esta contraposición debe pensarse como distinción entre élites «centralizadas» y élites «pluralistas». Esta afirmación puede incluso aplicarse a contextos como el norteamericano, en que, presentando una configuración pluralista, ${ }^{15}$ están sujetos a lógi cas de élite verticales (no estaría de más recordar la lección de C. W. M ills sobre la élite del poder). ${ }^{16}$ Las élites no sólo son plurales cuando están en una sociedad que no tiene una estratificación jerárquica y centralizada, sino, más bien, cuando su cultura piensa la estratificación social según criterios sel ectivos que no están ordenados jeráquicamente (bien sea en su versión orgánica, de estratos o funcional), sino relacionalmente. 
En el pasado ha existido una continua dialéctica entre estos dos tipos (élites «centralizadas» y élites «pluralistas»), con alternativas de concentración y dispersión, y con persistentes luchas hacia la estabilización o bien hacia la fragmentación. Todo ello dependía de la centralidad que se atribuía al poder político. Si queremos entender lo que sucede en la actualidad, se debe observar el fenómeno de las élites como fenómeno societario y no como fenómeno que depende esencialmente del sistema político (considerado como punto de referencia privilegiado).

\section{Las élites en la sociedad democrática moderna y postmoderna}

En la sociedad moderna, y con mayor razón en la postmoderna, las élites poseen al gunas características peculiares:

a) Son expresión de una peculiar relación de fuerza entre el Estado y la sociedad civil. ${ }^{17}$

b) Y lo son de formas muy diversas, según la semántica, respectivamente de gobierno político y de sociedad civil, de las que son portadoras o que prevalece en ellas. ${ }^{18}$

M ediante la intersección entre dos ejes, podemos distinguir cuatro tipos de élites (figura 3). D ichos ejes son los siguientes: el de las reivindicaciones

\section{Reivindicaciones que contienen las élites (entre ellas los derechos de ciudadanía)}

Para la estabilidad de los grupos políticamente fuertes

Élites del ESTATALISM 0

ESTABILIZADOR

H acia el sistema político
Para la emancipación de los grupos políticamente débiles

Élites del ESTATALISM O EM AN CIPAD OR

\section{Lealtad de las élites}

H acia la sociedad civil

Élites del SO CIETARISM O ESTABILIZAD OR

Élites del SO CIETARISM O EM AN CIPAD OR

Figura 3. Los cuatro tipos ideales de élites modernas. 
que contienen las élites (para la estabilidad del sistema o para su cambio en función de la emancipación de los grupos socialmente más débiles) y el de la lealtad dominante que, respectivamente, poseen las élites en sus relaciones con el sistema político o con la sociedad civil. Los cuatro tipos de élites son:

1. Élites del estatalismo estabilizador.

2. Élites del estatalismo emancipador.

3. Élites del societarismo estabilizador.

4. Élites del societarismo emancipador.

Estamos ante un mapa de las élites en el marco de la sociedad típicamente moderna. No es muy difícil insertar diversos ejemplos concretos.

En la modernidad, las configuraciones de las élites son la expresión de una combinación entre las orientaciones culturales de las élites y su grado de autonomía respecto a los órdenes políticos presentes, en concreto, respecto al sistema político del Estado nación establecido (figura 4).

Tenemos cuatro tipos de configuraciones:

- La ciudadanía estatal fragmentada.

- La ciudadanía societaria corporativa.

- La ciudadanía estatal centralizada.

- La ciudadanía societaria plural o de las autonomías sociales (en la que florecen las élites societarias).

\section{Grado de autonomía (respecto al sistema político) de las élites portadoras de los derechos}

Débil

En sentido
particular

Orientaciones

culturales de las élites

$\begin{array}{ccc}\text { En sentido } & \text { Débil } & \text { Fuerte } \\ \text { particular } & \begin{array}{c}\text { Ciudadanía } \\ \text { estatal } \\ \text { «fragmentada» }\end{array} & \begin{array}{c}\text { Ciudadanía } \\ \text { societaria } \\ \text { «corporativa» }\end{array} \\ \begin{array}{c}\text { En sentido } \\ \text { universal }\end{array} & \begin{array}{c}\text { Ciudadanía } \\ \text { estatal } \\ \text { «centralizada» }\end{array} & \begin{array}{c}\text { Ciudadanía } \\ \text { societaria } \\ \text { «plural» } \\ \text { «autonomías sociales }\end{array}\end{array}$

Figura 4. Tipología de las configuraciones de la ciudadanía como expresión de las orientaciones y del grado de autonomía de las élites

(portadoras de los derechos de ciudadanía). 
En los regímenes democráticos modernos, cuanto hemos dicho acerca de los órdenes sincrónicos, puede ser contemplado desde una clave más dinámica y diacrónica si se considera que el espacio analítico de emergencia de las élites de la sociedad civil se puede distinguir en cuatro códigos simbólicos diversos (figura 5).

D efinidos a partir del esquema AGIL, los cuatro códigos son:

A) Los códi gos técnicos. Las élites se seleccionan por la capacidad que tienen los individuos de manipular los medios y los instrumentos económicos. Por ejemplo, las élites tecnocráticas y manageriales.

G) Los códi gos estratégi cos. Las élites se forman a partir de la movilización que consiguen crear sobre objetivos de situación. Por ejemplo, las élites de los llamados «movimientos sociales».

I) Los códigos de pertenencia y de identificación asociativa. Las élites se configuran a partir de la capacidad de crear redes y gestionar la reticularidad en

\section{Área de} los intereses

\section{G}

\section{Códigos estratégicos}

(élites que se forman mediante

la movilización sobre objetivos de situación,

por ejemplo movimentos sociales)

A

Códigos técnicos

(élites seleccionadas por la capacidad

de manipulación de los medios e instrumentos económicos, por ejemplo las élites tecnocráticas y manageriales)

\section{Códigos de pertenencia y} de identificación asociativa

(élites que se forman para la tutela y promoción de las formas organizadas y reticulares de la socialidad)

\section{Códigos de valores}

(élites que se forman por adhesión a val ores últimos, o ideologías, por ejemplo los derechos humanos)

Área de las identidades

AREA A-G = Espacio de las élites que se forman a partir de los intereses.

AREA L-I = Espacio de las élites que se forman a partir de las identidades.

Figura 5. Los códigos simbólicos (de selección) de las élites en la democracia moderna. 
condiciones de globalización (capacidad empresarial asociativa) y, más en general, de tutela y promoción en las confrontaciones de las formaciones sociales intermedias (formas secundarias y primarias de la socialidad).

L) L os códigos de los valores. Las élites se crean por la adhesión que suscitan ciertas orientaciones de valores últimos, incluso las ideologías.

Las élites típicamente modernas especialmente se distinguen por los códigos A y G. Ciertamente, existe un Ilamamiento al código L, pero esta apelación, expresada como ideología declarada y fuerte (liberal o socialista) a lo largo de los siglos XVIII y XIX, progresivamente se hace menos clara y convincente, en concreto, en la segunda mitad del siglo xx con el declinar de las ideologías. El código I ha sido depuesto y sacrificado. Inicialmente, se ha expresado en las formas de la «simpatía» y de la socialidad realizada mediante el contrato (D avid $\mathrm{H}$ ume, Adam Smith, John Locke, etc.), que derivan en la formación de las élites del primer liberalismo. Con posterioridad, ha sido reelaborado - desde posiciones opuestas- por las élites socialistas a lo largo del XIX (pensemos, por ejemplo, en Saint-Simon, Proudhon, M arx y Engels).

La curiosidad histórica ante la que nos encontramos es la nueva emergencia, con formas totalmente inéditas y en condiciones totalmente diversas - es decir, de elevada complejidad-, del código «elitista social». Formas que presentan ciertas similitudes con al gunos movimientos socialistas, especialmente los más románticos y utópicos, del siglo pasado. La pregunta que se nos plantea es la siguiente: ¿Puede existir élite en la esfera de la integración social, en cuanto esfera diferenciada de los campos en que tradicionalmente han emergido las élites (es decir, entre el mercado, la política y la ideología)?

\section{La emergencia de nuevas «élites societarias»: poderes sociales de la sociedad civil}

La modernidad construye una ciudadanía cuyos componentes, en términos de derechos, aluden a élites espećficas. Si nos atenemos a la distinción entre dere chos civiles, políticos, sociales y humanos, nos encontramos con las correspondientes élites. A su vez, el proceso de construcción de la ciudadanía democrática genera nuevas élites, que se definen en función de los derechos que se reivindican con posterioridad (derechos que son considerados universales, aunque de hecho no lo son).

La modernidad se inicia con la emergencia de las élites lib (liberales). De forma inmediata, por reacción y distinción, surgirán las élites lab (socialistas). Las primeras (lib) hacen progresar los derechos civiles netamente burgueses. Tratan de evitar sistemas políticos masificados. Pero, al mismo tiempo, erosionan las pertenencias comunitarias y relacionales a partir de una visión abstracta de los derechos humanos. Por su parte, las segundas (lab) promueven los derechos políticos universales y, posteriormente, los derechos de welfare típicos de los estratos obreros y de los comprometidos en un trabajo asalariado. Transforman las comunidades en «colectividades». Y todo ello lo hacen a 
partir de una concepción ideológica de los derechos como titulaciones de categorías sociales abstractas.

Siguiendo la terminología adoptada con anterioridad (figures 3 y 4), podemos decir que las élites lib tienen un carácter prevalentemente societario, inicialmente emancipador $y$, con posterioridad, estabilizador. D efienden una ciudadanía plural y fragmentada. Sin embargo, las élites lab poseen un carácter estatal, inicial mente emancipador y, posteriormente, estabilizador. Favorecen una ciudadanía centralizada y corporativa.

No resulta arriesgado decir que la modernidad se encuentra ante límites insuperables en un determinado momento histórico. Concretamente, aquél en el que las élites ya no pueden ser ni puramente lib, ni puramente lab. Es decir, cuando la construcción de la sociedad ya no se puede organizar a partir de la distinción lib versus lab. Actualmente, el fin de la modernidad se constata en el siguiente hecho: lib y lab deben llegar a compromisos que derivan en una hibridación y apoyo recíproco. El horizonte, más allá del cual la modernidad no puede avanzar, está marcado por la persistencia de élites neo-lib/lab que intentan sobrevivir a la modernidad mediante la alianza de viejas configuraciones lib y lab. M uchos denominan a este camino «welfare mix» 0 «tercera vía». ${ }^{19}$

Pero las élites neo-lib/lab tienen un defecto: la incapacidad de reproducirse según los viejos códigos. El motivo no es otro que la progresiva erosión de las bases estructurales y culturales de la reproducción lib y lab. $N$ acen élites que contienen una multiplicidad de intereses (en el sentido de multi-stakeholders), cuya natural eza posee un carácrer asociativo y reticular. La construcción de la sociedad se plantea a partir de una nueva distinción: élites lib/lab de un lado, y élites nuevas de otro. Pero ¿cuáles son estas nuevas élites? Son grupos selectos que expresan la emergencia de una nueva configuración de ciudadanía societaria. M erece la pena hacer un intento para diseñar su perfil.

Estamos ante élites que no se apoyan en principios abstractos de ciudadanía, sino en principios concretos. No razonan en términos de comprimir o extender, de exclusión o inclusión, sino de generalización y diferenciación según las pertenencias. La estratificación social que expresan ya no es la de cla ses 0 grupos premodernos (definidos a partir de ciertos privilegios de estatus) o modernos (definidos en relación con el mercado capitalista). Sino de estratos sociales que se diferencian en función de condiciones y estilos de vida fuertemente individualizados. Su identidad es la del «hombre plural». ${ }^{20} \mathrm{~N}$ o nacen ni del mercado, ni del Estado, ni de un mix de ambos. M ás bien de lo que está fuera del mercado y del Estado. Su poder no es político en sentido moderno (es decir, por referencia al Estado), sino que es social: alude a las reglas asociativas y disociativas. Las reglas de distribución de los recursos que propugnan y utilizan estas élites no son ni de tipo asistencial, ni de tipo redistributivo. Poseen un carácter distributivo y conmutativo, cuya natural eza rechaza los parámetros 
económicos y políticos típicos de la modernidad. No apoyan ni la idea de un esta do mínimo, ni la de un big government. M ás bien la idea de un estado subsidiario. D e esta forma redefinen la política. Los sujetos de ciudadanía a los que nos estamos refiriendo no son ya ni las comunidades tradicionales, ni los individuos en cuanto pertenecientes a entidades colectivas abstractas (la clase obrera, o incluso la mujer o los excluidos, etc.). Son los individuos en cuanto pertenecientes a redes sociales dotadas de «subjetividad social». Éstos son los sujetos que contienen el nuevo político, le politique, distinto de la politique, según la terminología de Caille, ${ }^{21}$ que retoma el pensamiento de F. Burdeau.

En nuestra terminología, son élites anti-lib/lab. Estas nuevas élites societarias emergen por razones históricas conectadas a la dinámica de la democracia como sistema societario, y no sólo como régimen político. La democracia, como forma de gobierno, se excede a sí mima en una peculiar configuración societaria. Ésta, en determinados aspectos, es pluralista como en la modernidad (sigue su caminar isotrópico, de uniforme expansión en todas las direcciones), ${ }^{22}$ pero al mismo tiempo se distancia en cuanto que desarrolla nuevos principios de diferenciación.

El pluralismo hodierno contiene élites diferentes de las del pasado, ya que es un punto de vista sobre la sociedad que:

- Introduce (a partir de la teoría de la democracia) un principio diferenciador diverso del individualista, que había sido ubicado como fundamento de la sociedad moderna. El nuevo principio de diferenciación alude a las pertenencias que tienen las personas en sus formaciones (reagrupamientos) sociales.

- De acuerdo con tal principio, atribuye los derechos de ciudadanía (civiles, políticos, sociales y humanos) a las «subjetividades sociales».

- Y todo ello lo hace a partir de una nueva concepción relacional del conocimiento y de la acción que repercute - en sentido pluralista- en la cultura y las praxis propiamiente humanas, es decir, distintivas - en un nuevo sentido- de lo humano.

La hodierna pluralización de las élites, bajo las condiciones de una democracia que se desarrolla según un código de ciudadanía societaria, es un efecto de estos cambios más generales, cambios que marcan el nacimiento de otra formación histórico-social.

En este escenario, se replantea el antiguo interrogante que siempre ha opuesto entre sí a elitistas y pluralistas: ¿quién gobierna la sociedad? En la actualidad, la pregunta debe ser planteada con una nueva sensibilidad. El argumen-

\section{Véase A. Caille (1993).}

22. «El intento de captar el cambio a partir de los procesos de diferenciación hace creer que el fenómeno del pluralismo, relevante por las diferenciaciones, no es otra cosa que una de las muchas caras de la complejidad. Aunque también es verdad lo contrario: la complejidad es un aspecto emergente del pluralismo; la sociedad compleja no era más que la sociedad pluralista» (F. Barbano, 1999: 29). 
to es el siguiente: el gobierno de una sociedad plural que se ha hecho comple ja y globalizada posee un sentido diferente al que tenía en las sociedades liberales y democráticas del pasado. En el centro está la sociedad que vive en la «cultura del presente», 23

H asta el día de hoy, la pregunta iquién gobierna la sociedad?, ha diferenciado a los elitistas de los pluralistas de la siguiente forma. Según los elitistas, son las élites las que dominan y gobiernan, en cuanto que actúan para una distribución desigual de los recursos, la hacen acumulativa y, en al gunos casos, irreversible. El elitismo perpetúa la imagen secular de la política como lucha y dominio de unos pocos sobre muchos. El poder se encuentra estrictamente ligado a la posesión y el control de los recursos económicos, organizativos y simbólicos. Las élites contemplan el proceso político como tendencialmente monocéntrico, ya que para ellas el poder - entendido como capacidad de conseguir los propios objetivos en presencia de una oposición - tiende a crear una estructura jerárquica permanente. Piensan la política en términos de juegos de suma cero. En consecuencia, resaltan la emergencia de grupos selectos e, in extremis, de una sola élite.

Sin embargo, según los pluralistas, la imagen es opuesta. D escriben la política como competición entre un amplio número de fuerzas heterogéneas, y como mediación entre los múltiples intereses presentes en la sociedad. Piensan la política como juegos de suma mayor de cero. En consecuencia, el poder es un recurso que jamás puede ser posé́do de forma estable. Su distribución tiene un carácter variable, es decir, de relativa difusión entre una constelación de fuerzas en continuo cambio. En consecuencia, no puede dar lugar a una estructura jerárquica permanente.

Ciertamente, existen muchas posiciones diferentes y diversas aproximaciones al tema. Por ejemplo, el elitismo democrático acoge las críticas liberales al elitismo clásico. D e esta forma, el juego democrático es descrito y pensado como competición entre élites «abiertas» (accesibles, no cerradas o adscriptivas) hacia los ciudadanos electores. ${ }^{24} \mathrm{El}$ mismo juego democrático es conce bido como un método para la elección de líderes que representan élites competitivas, procedentes del mercado y, en consecuencia, expresión de procesos selectivos de carácter managerial ${ }^{25}$ o económico. ${ }^{26}$ El elitismo clásico o tradicional debe repensarse en términos nuevos o críticos. ${ }^{27}$

Sin embargo, está claro que los factores sociológicos fundamentales son los mismos: se trata de variables que siempre aluden a los terrenos del mercado y del estado, naturalmente con sus símbolos y representaciones culturales. C on tendencias que oscilan entre las posiciones oligárquicas (como piensa Charles Wright M ills) y las poliárquicas (Robert D ahl habla de «democracia poliár- 
quica»). Las élites democráticas típicamente modernas actúan a partir de ventajas competitivas ${ }^{28}$ y se presentan, según Angelo Panebianco, ${ }^{29}$ como élites de «guerreros democráticos».

¿Tiene aún razón de ser la antigua oposición entre pluralistas y elitistas?

Existen diversos planteamientos que defienden su vigencia. Un buen ejemplo es la tesis de Filippo Barbano cuando sostiene que, desde la Segunda Guerra M undial hasta nuestros días, «la Europa continental democrática se ha transformado en una sociedad plural, mientras que ha permanecido como un entorno sin cultura pluralista y con la ausencia del pluralismo como cultura política». ${ }^{30} \mathrm{Si}$ se siguen sus planteamientos, se debería deducir que la Europa continental democrática estaría caracterizada por un elitismo de tipo tradicional, poco influenciado por los procesos de modernización. Ésta es también la tesis de Giovanna Zincone cuando, al comparar la Europa continental democrática con los Estados U nidos, subraya que nos encontramos ante dos configuraciones opuestas: «Un sistema centralizado, parlamentario y consociativo, el de la Europa continental democrática. Un sistema descentralizado, societario (es decir, con un estado débil respecto a los poderes sociales), presidencial (con un ejecutivo elegido de manera formal directamente por el pueblo), mayoritario y poco asentado en los partidos, el americano. Bipartidismo en Estados U nidos, pluripartidismo en la Europa continental democrática».31

Ciertamente, la Europa continental democrática es un contexto que, comparado con los países anglosajones, posee una débil sociedad civil en sentido moderno. ${ }^{32}$ Sin embargo, hay que preguntarse si la dirección de Europa debería ser seguir el modelo americano. En el fondo, este modelo plantea que el antiguo dilema entre pluralismo y elitismo se resuelve con una teoría democrática de las élites, o bien con el enforcement de élites democráticas, presuponiendo implícita o explícitamente que el sistema político (democrático) deriva del mercado y alude a sus lógicas, a sus actores e intereses. Si el problema es entender las nuevas élites, es decir, qué son, dónde emergen y cuáles son sus características, el planteamiento politológico de Zincone-como el de otros muchos- es parcial. Y no sólo porque limita la observación, una vez más, a la planteada desde el sistema político, sino también porque ignora los cambios a los que está sometido el modelo americano y no tiene en cuenta los escenarios postmodernos.

Para ver las nuevas élites, es necesario realizar una observación diversa, 0 sea, plantear el análisis desde otros puntos de observación. D eben mantenerse las dinámicas elitistas y pluralistas en cuanto que son tipos ideales y per- 
manecen. Pero, al mismo tiempo, es necesario contemplar como, en la posmodernidad, cambian las condiciones complejas (los escenarios) y la distinción directriz en la que las élites 0 , viceversa, los grupos plurales, actúan o pueden actuar. Los escenarios son los de una acentuada diferenciación societaria, de manera que:

- El sistema político-institucional y el poder político no tienen ya en el mercado su base ni su referente primario.

- Emerge una nueva distinción para definir las tendencias de formación de las élites: la distinción entre sociedades que, siendo diferenciadas, se organizan a partir de un principio cultural y organizativo capaz o no de pluralismo auténtico y activo. ${ }^{33}$ La mayor parte de las sociedades no son pluralistas, en cuanto que se organizan desde otros códigos (estatalizantes, globalizantes 0 «sistémicos»). Sin embargo, al gunas sociedades se organizan en sentido pluralista, ya que se orientan hacia una ciudadanía societa ria postmoderna. Es en ellas donde nacen las auténticas nuevas élites.

En el caso de la Europa continental democrática, se puede estar de acuerdo en que el problema es el siguiente: una pluralización (como diferenciación) de la sociedad, fenómeno que tiene lugar bajo la ausencia de un pluralismo cultural adecuado para gestionar tal proceso.

La solución propuesta por Barbano - adoptar «el pluralismo como prueba», como experimento, como navegación a la vista, como planteamiento de adaptación contingente, momento por momento- es útil y necesaria, pero no satisfactoria. N os deja a merced del proceso que criticamos. Una solución alternativa más concreta consiste en reconocer la necesidad de élites de la socie dad civil. Ahora bien, entendiendo ésta última no sólo como tercer sector o privado social, sino como conjunto de actores que asumen estilos relacionales, es decir, que no se comportan ni como clases dominantes de tipo político, ni como actores de mercado orientados al mero beneficio o a la defensa de intereses particulares y corporativos (por ejemplo sindicales). La sociedad posib/lab necesita una élite civil, hecha de capacidad emprendedora cívica-social-relacional y diferente de los esquemas políticos y económicos.

No estamos hablando de deseos o esperanzas abstractas. Aunque invisibles y sumergidas, la afloración de estas élites societarias y civiles puede constatarse empíricamente. ${ }^{34}$ Su desarrollo depende:

- De la posición estructural en que se ubican los actores.

- Del código cultural que elaboran.

- De las prácticas sociales que activan.

33. Sociedades plurales con pluralismo y sin pluralismo, si permanecemos en la terminología de F. BARBAN O (1999); o bien de «ciudadanía profunda», en la terminología de P. B. CLARKE (1996).

34. Véanse J. L. Laville y R. Sain Saulieu (1997), P. D on ati (1997). 
No solamente debemos ver estas élites como expresión del llamado tercer sector (voluntariado, cooperación social, asociacionismo social, fundaciones, trusts, etc.), sino como manifestación de un movimiento que desplaza a todo el sistema societario. Aún más, el Ilamado non profit generalmente no es tal, incluso puede no ser una categoría social innovadora cuando se piensa en términos modernos, es decir, como actividad de beneficiencia o de puro altruismo, antes que como actividad empresarial. ${ }^{35}$ Empíricamente, las nuevas élites societarias están en la empresarialidad social de la sociedad civil, aquélla que no se piensa en función de la hegemonía política (ya sea de derechas o de izquierdas, ya sea lib o lab).

D esde un «proceso de abstracción» de los códigos simbólicos de las élites modernas, pasando a través de la postmodernidad (figura 5), podemos generalizar de la siguiente forma el espacio de las variables que definen la emergencia de las élites en sociedades altamente diferenciadas (figura 6):

\section{G}

Élites que persiguen fines y objetivos de situación

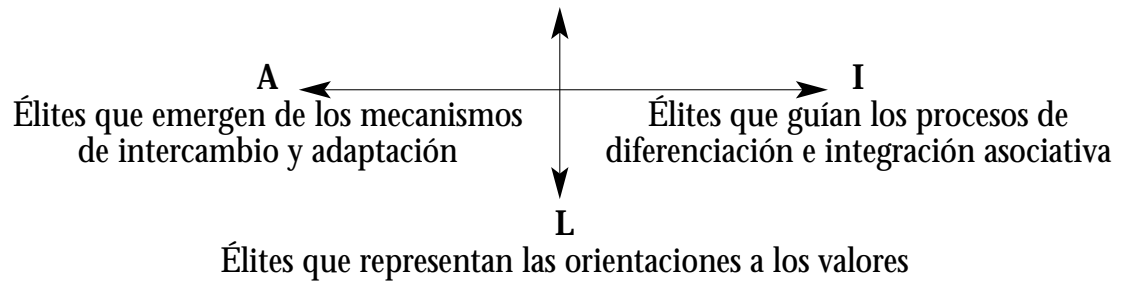

Eje A-I: dimensiones estructurales y de coordinación Eje L-G : dimensiones de sentido y legitimación

Figura 6. Los componentes de diferenciación de las élites en configuraciones postmodernas.

A) Las élites de la effera económica nacen de nuevos mecanismos de selección en el intercambio y en la adaptación a las condiciones de globalización: élites financieras, mediáticas o que gestionan la información a escala mundial, etc. ${ }^{36}$

G) Las élites de la effera política se forman mediante la persecución de fines y objetivos de situación: si se las quiere identificar, es necesario establecer su distinción con respecto a otros componentes de la diferenciación de las élites, es decir, económicos, de integración y culturales. Esto puede contemplarse en las nuevas élites políticas que guían el proceso de integración europea. ${ }^{37}$ 
I) Las élites de la esfera social se generan allí donde nacen nuevas reglas de intercambio social (no político y no económico) finalizado en la diferenciación e integración asociativa o en la organización de redes asociativas. ${ }^{38}$

L) Las élites dela efera cultural (latente) reflejan la emergencia de nuevas orientaciones de sentido hacia los valores últimos o la reivindicación del compromiso hacia los val ores. ${ }^{39}$

Las nuevas élites manifiestan la diferenciación de los «poderes» en las dimensiones analíticas (económicas, políticas, sociales y culturales). En concreto, asistimos a la emergencia de poderes sociales y civiles diversos de los económicos y políticos. La dinámica interna de las esferas sociales que producen las nuevas élites societarias es expresión de esferas asociativas (I) que, sólo parcialmente, actúan como actores (por ejemplo lobbies) ligados al mercado. ${ }^{40}$ M ás bien ocurre lo contrario, muchas de estas esferas sociales funcionalizan para sí los restantes componentes, incluso el mercado en sentido capitalista (de la figura 6).

Esto no impide que sigan existiendo las viejas élites que apelan a la mera opinión-influencia, 0 al poder político de los partidos, o al poder económico del intercambio mercantil, 0 a la capacidad de movilización de los llamados «movimientos sociales». Ahora bien, las élites que se forman de esta manera ya no pueden aportar nada nuevo. Son las reproducciones de los viejos códigos. El nuevo código es el de las «élites societarias». Éstas se caracterizan por la producción y regulación de procesos y estándares de la integración asociativa basados en distinciones socioculturales diversas de las del poder económico en sentido moderno y del dinero.

Sólo estas élites tienen en cuenta lo que llamanos «el fin del hombre político», ${ }^{41}$ tal y como lo ha pensado la modernidad, y la localización comunicativa que se deriva - por reacción- de la globalización. ${ }^{42}$ Sólo estas élites socie tarias pueden construir un tejido social sobre el que edificar nuevas formas de «gobierno» (en sentido analítico) de la sociedad, más allá de las fluctuaciones de los mercados, de la impersonalidad y de la manipulación de los sistemas mediáticos, del surgimiento de los conflictos étnicos y, más ampliamente, de las colisiones de civilidad.

38. Véase E. O. W RIGHT (1995).

39. Véase P. LICHTERM AN (1996).

40. En los Estados U nidos, los actores societarios a los que aludimos generalmente están ubicados en el mercado. No debemos de olvidar que en este contexto cultural no existe gran diferencia respecto al social (el mercado en sentido americano engloba todo aquello que en Europa constituye una esfera social diferente).

41. Véase L. LANGMAN (1998).

42. «Agoraphobia and the renaissance of locality», como la denomina Z. BAU m AN (1998). Véase también B. SAN GUANINI (1998). 


\section{Bibliografía}

Ahrne, G. (1998). «Civil Society and Uncivil O rganizations», en J. C. AlexAn der (ed.), Real Civil Societies: Dilemmas of Institutionalization, Sage, Londres, p. 84-95. Alberon I, F. (1973). L'élite senza potere: ricerca sociologica sul divismo, Bompiani, M ilán. Albertoni, E. A. (1993). «Élite», en E. Berti, G. Cam pan In I (comp.), Dizionario delle idee politiche, Ediciones Ave, Roma, p. 270-279.

Albrow, M . (1996). The Global Age, Polity Press, C ambridge.

BACH RACH, P. (1967). The Theory of D emocratic Elitism, A Critique.

Barban O, F. (1999). Pluralismo. Un lessico per la democrazia, Bollati Boringhieri, Turín. BARBer, B.R. (1998). A Place for U s. H ow to M ake Society Civil and D emocracy Strong, $\mathrm{H}$ ill and Wang, N ueva York.

Baum an , Z. (1998). Globalization. The H uman Consequences, Polity Press, O xford. BerLe, Jr. A. A. (1959). Power Without Property. A N ew D evelopment in American Political Economy, M ac M illan, N ueva York.

Borzaga, C.; M ITTONE, L. (1997). The M ulti-Stakeholders versus the N on profit O rganization, University of Trento, D iscussion Paper $n .7$.

BuRn H AM , J. (1992). La rivoluzionemanageriale, Bollati Boringhieri, Turín.

CaILLÉ, A. (1993). La démi ssion desclercs. La crise des sciences sociales et l'oubli du politique, La D écouverte, París.

Clarke, P. B. (1996). D eep Citizenship, Pluto Press, Londres-C hicago.

CROWLEY, J. «European Integration: Sociological Process or Political Project?», en Innovation: The European Journal of Social Sciences, vol. 9, n. 2, junio 1996, p. 149-160.

D AH L, R. A. (1982). Dilemmas of pluralist democracy: autonomy, N ew H aven, Yale University.

- (1999). La democracia: una guía para los ciudadanos, Taurus, M adrid.

D o N ATI, P. (1991). Teoria relazionale della società, Angeli, M ilán.

- (1993). La cittadinanza societaria, Laterza, Roma-Bari.

- (1997). «Alla ricerca di una società civile. Che cosa dobbiamo fare per aumentare le capacità di civilizzazione del Paese?», en P. D o N ATI (comp.), La società civile in Italia, M ondadori, M ilán, p. 21-80.

Giddens, A. (1998). The Third Way. The Renewal of Social Democracy, Polity Press, Cambridge.

GINER, S. (1996). «Sociedad Civil», en E. Díaz (ed.), Filosofía política, vol. II. Teoría del Estado, en Enciclopedia I beroamericana de Filosofia, M adrid, Trotta y C sic.

H ELD, D . (1991). M odel os de democracia, Alianza U niversidad Ciencias Sociales, Madrid.

H IRST, P. (1997). From statism to pluralism. D emocracy, civil society and global politics, U CL Press, Londres.

KelLeR, S. (1963). Beyond the Ruling Class. Strategic Élites in M odern Societies, Random H ouse, N ueva York (segunda ed. 1992).

LAH IRE, B. (1998). L'homme pluriel. Les ressorts de l'action, N athan, París.

LANGM AN , L. (1998). «The End of Political M an (and Woman)», en G. GASPARIN I (ed.), N ation, Ethnicity, M inority and Border, ISI G, Gorizia, p. 15-36.

Laville, J.-L.; Sain SAulieu, R. (1997). Sociologie del'association. D es organisationsà l'e preuve du changement social, D esclée de Brouwer, París.

Lich Term An, P. (1996). The Search for a Political Community. American Activists Reinventing $\mathrm{C}$ ommitment, $\mathrm{C}$ ambridge U niversity Press, C ambridge. 
M ILLS, C. W. (1993). La élite del poder, Fondo de Cultura Económica, M éjico. M ONGARDIN I, C. (1993). La cultura del presente. Tempo estoria nella tarda modernità, Angeli, Milán.

O RNAGHI, L. (1994). La virtù dei migliori: le élites, la democrazia, I'Italia, II M ulino, Bolonia.

Panebian Co, A. (1997). Guerrieri democratici. Le democrazie ela politica di potenza, II Mulino, Bolonia.

PorTer, M. E. (1999). Il vantaggio competitivo, Ediciones di Comunità, Turín.

SAN GUAN IN I, B. (1998). Locale \& M edia N ordest Italia. Costruire il «mondo locale» nell'epoca dei media, Ediciones Goliardiche, Trieste.

W RIGHT, E. O . (1995). (ed.), Associations and D emocracy, Verso, Londres-N uevaYork. ZIN CONE, G. (1995). USA con cautela. II sistema politico italiano e il modello americano, D onzelli, Roma. 